\title{
ON THE RESPONSE OF IMPACTING COMPLIANT FLEX RUN
}

\author{
T. T. Akano ${ }^{1,}{ }^{*}$ and 0. A. Fakinlede ${ }^{2}$ \\ 1,2 DePARTMENT OF SYSTEMS ENGINEERING, UNIVERSITY OF LAGOS, AKoKA, LAGOS STATE, NIGERIA \\ E-mail addresses.1takano@unilag.edu.ng; 2 oafak@unilag.edu.ng
}

\begin{abstract}
Damage caused by impacts of structures can result in catastrophic failure, including huge loss of life. A typical example involves a Flexrun which is particularly vulnerable to several impacts on the ground surface. It is, therefore, becoming increasingly important to be able to model and predict such phenomena. The impact of an impacting compliant system such as a Flexrun on the ground surface is simulated by the general purpose explicit dynamic finite element program $L S$ DYNA. The complicated geometry has been modeled in Solid Edge ST6 before being imported into LS PrePost/LS-DYNA for the required analysis. The response characteristics of the Flexrun show the effect of impacting velocity on strain and stress histories of the mechanism. Results reveal that within the impacting velocity of $15 \mathrm{~m} / \mathrm{s}$, the effective stress and strain responses remain unchanged.
\end{abstract}

Keywords: compliant mechanism, impact-contact, LS-DYNA, hyperelastic, Flex-Run

\section{INTRODUCTION}

Compliant mechanisms (CMs), by definition, are mechanisms that gain some or all of their motion from the deflection of their members. This makes them very different from traditional rigid-body mechanisms which have rigid links connected by kinematic pairs such as pin joints, sliding joints, and cams[1]. The Application domain of CMs range from aerospace, to mechanical, automotive, biomedical, orthopaedic and sporting systems. A typical example of a sporting CM is the FlexRun used by amputated athletes. Such mechanisms are subjected to contact/impact problems as shown in Figures 1 and 2 where amputated athletes were using the Flex-Run

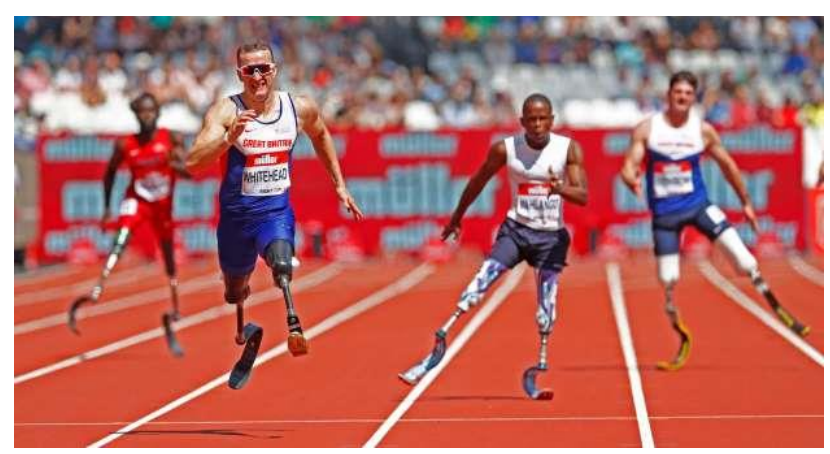

Figure1 : Athletes using the flex-run during the men's 200m T42 2016 at the London Anniversary Games at Queen Elizabeth Olympic Park [2].

The impact compliant system has been used in the design and analysis of the Energy Storing Feet (ESF), a useful feet prototype for the prosthesis. The principle which energy storage depends upon entered prosthetic design by 1981 beginning with the Model \& Instrument Works Seattle Foot. The designed foot deflects through the middle causing potential energy to be effectively stored. The foot behaves as an elastic material such that after each step, the stored energy causes the foot returns to its original shape[3]. The introduction of the Ǒssur FlexFoot ushered the second generation of the ESF in 1987. This work, the material deflected consist of not just the foot alone, making it mimic the typical human leg consisting of the shank, toe, foot and heel of the foot, allowing for effective storage of potential energy and more energy return for push-off [4].

The step-to-step transition of the Flexrun is inherited from the pendulum theory, thereby giving more benefits associated with the ESF. Hafner et al. [5] summarily stated that the benefits of ESF are limited to the concept of self-selected working speed, in their review of the benefits of the ESF in their article of storage of energy and prosthesis responses. Accordingly, the majority of examined studies shows that the type of foot does not significantly affect self-selected working speed. Statistically, there was an increase in walking velocity when ESF was used but the amount of improvement did not reach any reasonable significance.

In contrary, this consistently caused a decrease in the magnitude of the peak vertical forces acting upon the sound side. About 5 percent of this was characterized in

\footnotetext{
* Corresponding author, tel: + 234-803-849-6150
} 
the first-generation of ESF indicating a slight improvement.

Further studies on the second-generation ESF has seen an improvement with decreased by almost 20 percent which was regarded as the industry's earliest successes in replicating the energy restoration of the Flex Run. However, this has resulted in partial sparing of the sound-side limb from the collision inherent in the stepto-step transitions.

There is an increase in the use of composite materials for high duty components which require not only excellent specific stiffness and strength but also impact capability and damage tolerance. The particular applications where these properties are at a premium include aerospace components such as wings, fan blades and containment casings[6], green energy applications such as the wind and tidal turbine blades, military equipment including vehicle blast protection systems and marine and even submarine systems and compliant sporting systems such as the Flexrun.A common feature of such applications is the imperative to keep weight as low as possible and to design to optimise impact performance.

The current state of the art in composites impact analysis and verification places high demands regarding computing time and expensive testing[7], reviews on low-velocity impact[8], impact resistance[9], and the role of fibre reinforcement architecture [10]. The analysis is typically performed using explicit finite element (FE) code [11], a feature of which is that the maximum size of the time step is related to the smallest element dimension in the model.

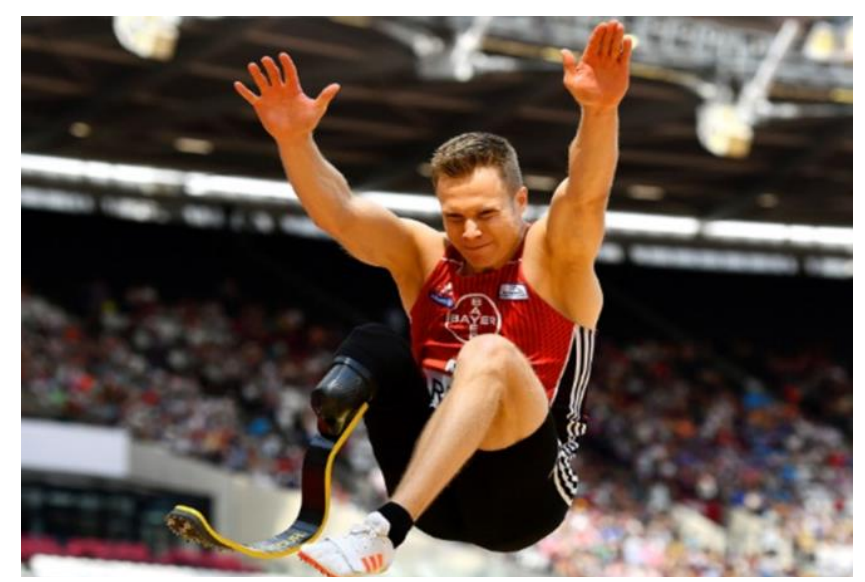

Figure 2: Germany's Markus Rehm jumps at the Muller Anniversary Games [12]

The impact phenomenon is characterized by abrupt changes in the value of system variables with most visible discontinuities in the system velocities. Other effects directly related are the vibration propagation on the system components, local elastic deformations at the contact zone, and energy dissipation. The selection of an adequate velocity model plays a key role in the correct design and analysis of any impacting system.

The field of mechanics and biomechanics of prosthetic feet has seen wide ranges of researchers have gone done the line and others are still emanating. Millerand Childress[13] conducted mechanical testing of the ReFlex VSP(TM) Foot on the pylon alone and the pylon and forefoot system. Sauders et al.[14]developed an approach for prosthetic foot design incorporating motion analysis, mechanical testing and computer analysis. Gitter et al.[15] determined the biomechanical adaptations used by the below-knee amputee while wearing a conventional prosthetic foot and to assess the influence of energy storing prosthetic feet on these adaptations.Curtzeet al.[16]determined the roll-over characteristics of a broad range of prosthetic feet and examined the effect of a variety of shoes on these characteristics.South et al.[17] developed a rapid prototyping framework using selective laser sintering (SLS) for the creation of prosthetic feet that can be as a means to quantify the influence of varying foot stiffness on transition amputee walking. Frigo et al.[18]analysed the mechanical characteristics of the prosthetic feet to the purpose of defining criteria for proper sizing and adaptation. Bonnet et al.[19] combined finite element modelling and gait analysis to calculate the strain, stress and energy stored in the foot along the stance phase for self-selected and fast walking speeds.

To correctly design and analyse impacting compliant system, the selection of most adequate velocity is a huge criterion. Noticeable damage is experienced when structural systems and materials are subject to impact under both high and low velocities. This impact, if not well understood can cause failure of the impacting system. It is, therefore, becoming increasingly important to be able to model and predict such phenomena.

The aim of this paper is to perform a numerical analysis of a Flexrun impacting by an athlete. The numerical analysis algorithm is numerically stable and efficient [20], and runs in a matter of a few seconds on a modern laptop computer.LS-DYNA [21], an advanced generalpurpose multiphysics simulation software package is used and their response characteristics are investigated for the impact analysis.LS-DYNA was selected due to its robust capability of handling impact phenomenon.

\section{DEVELOPMENT OF THE FINITE ELEMENT MODEL}

\subsection{Ogden Material Model}

To implement the finite element analysis of nearly incompressible material models, the strain energy density function $\Psi(C)$ for such material is often decoupled in terms of the dilatation and deviatoric parts as

$$
\Psi(C)=\Psi(\bar{C})+U(J)
$$


Where

$$
\begin{aligned}
& \Psi(\bar{C})=\mu_{r}(\operatorname{tr} C-3) \\
& U(J)=\beta(J-1)^{2} \\
& \mu_{r}=\frac{1}{2} \sum_{i=1}^{n} \mu_{i} ; \beta=\frac{k_{i}}{2}
\end{aligned}
$$

$k$ and $\mu$ are the material properties known as bulk and shear moduli respectively; $J$ is the Jacobian of the deformation gradient; $C$ is Right Cauchy-Green tensor. The strain energy density could be expressed in terms of the principal stretches $\lambda_{\mathrm{j}}$ as

$$
\begin{aligned}
\Psi\left(\lambda_{1}, \lambda_{2}, \lambda_{3}\right)= & {\left[\sum_{p=1}^{n} \frac{\mu_{p}}{a_{p}}\left(\bar{\lambda}_{1}^{a_{p}}+\bar{\lambda}_{2}^{a_{p}}+\bar{\lambda}_{3}^{a_{p}}-3\right)\right.} \\
& \left.+\sum_{p=1}^{n} \beta(J-1)^{2}\right]
\end{aligned}
$$

The principal components of the Cauchy stress are given by[22]

$$
\sigma_{i}=\frac{\lambda_{i}}{\lambda_{1} \lambda_{2} \lambda_{3}} \frac{\partial \Psi}{\partial \lambda_{i}} \quad i=1,2,3
$$

The strain energy potential can be written as either function of the principal stretch ratios or as a function of the invariants of the strain tensor $I_{1}, I_{2}, I_{3}$

$$
\begin{gathered}
I_{1}=\lambda_{1}^{2}+\lambda_{2}^{2}+\lambda_{3}^{2} \\
I_{2}=\lambda_{1}^{2} \lambda_{2}^{2}+\lambda_{2}^{2} \lambda_{3}^{2}+\lambda_{3}^{2} \lambda_{1}^{2} \\
I_{2}=\lambda_{1}^{2} \lambda_{2}^{2} \lambda_{3}^{2}
\end{gathered}
$$

The modified distortion stretches and invariants are then:

$$
\bar{\lambda}_{j}=J^{-1 / 3} \lambda_{j} \quad j=1,2,3
$$

and

$$
\begin{gathered}
\bar{I}_{1}=J^{-2 / 3} I_{1} \\
\bar{I}_{2}=J^{-4 / 3} I_{2} \\
\bar{I}_{1}=J^{2}
\end{gathered}
$$

Eq. (6) could now be rewritten as

$$
\begin{aligned}
\lambda_{i} \frac{\partial \Psi}{\partial \lambda_{i}}=\sum_{p=1}^{n} \frac{\mu_{p}}{a_{p}}( & -2 / 3 J^{-5 / 5} \lambda_{i} \frac{\partial J}{\partial \lambda_{i}}\left(\lambda_{1}^{a_{p}}+\lambda_{2}^{a_{p}}+\lambda_{3}^{a_{p}}\right) \\
& \left.+J^{-2 / 3} a_{p} \lambda_{i}^{a_{p}}\right) \\
& +\sum_{p=1}^{n} 2 \beta(J-1) \lambda_{1} \frac{\partial J}{\partial \lambda_{1}}
\end{aligned}
$$

Since, $=\lambda_{1} \lambda_{2} \lambda_{3}$ we have

$$
\lambda_{i} \frac{\partial J}{\partial \lambda_{i}}=\lambda_{1} \lambda_{2} \lambda_{3}=J
$$

Hence,

$$
\begin{gathered}
\lambda_{i} \frac{\partial \Psi}{\partial \lambda_{i}}=\left[\sum_{p=1}^{n} \frac{\mu_{p}}{a_{p}} J^{-2 / 3}\left(a_{p} \lambda_{i}^{a_{p}}-2 / 3\left(\lambda_{1}^{a_{p}}+\lambda_{2}^{a_{p}}+\lambda_{3}^{a_{p}}\right)\right)\right. \\
+\sum_{p=1}^{n} 2 \beta J(J-1)
\end{gathered}
$$

Proceeding with the constitutive tensor, the principal Cauchy stresses are therefore given as

$$
\begin{gathered}
\sigma_{i}=\left[\sum_{p=1}^{n} \frac{\mu_{p}}{a_{p}} J^{-5 / 3}\left(a_{p} \lambda_{i}^{a_{p}}-2 / 3\left(\lambda_{1}^{a_{p}}+\lambda_{2}^{a_{p}}+\lambda_{3}^{a_{p}}\right)\right)\right. \\
\left.+\sum_{p=1}^{n} 2 \beta J(J-1)\right]
\end{gathered}
$$

\subsection{Impact Analysis}

Figures 3-5 shows the Flex-Run geometry in orthographic views. The Flex-run impacts the ground surface as shown. The modelling of the Flexrun was carried out in Solid Edge ST 6, imported into LS PrePost and automatically meshed while LS-DYNA performed the solution. The Flex run material is carbon-fiber-reinforced polymer with average density of $1740 \mathrm{Kg} / \mathrm{m}^{3}$ and Young's modulus of $72 \mathrm{GPa}$ while the target surface is idealized as turf made from medium density polypropylene with average density of $980 \mathrm{~kg} / \mathrm{m}^{3}$ and Young's modulus of 1.8GPa. In the implementation of the material properties, the Ogden model was used. Poisson ratio $v$ and Ogden exponents' $\alpha_{p}$ values of 0.49995 and 2 were used which reduces the Ogden model to the nearly incompressible hyperelastic model when the summation limit $n=1$. The entire FE model was built with the necessary boundary conditions (Figure 6).

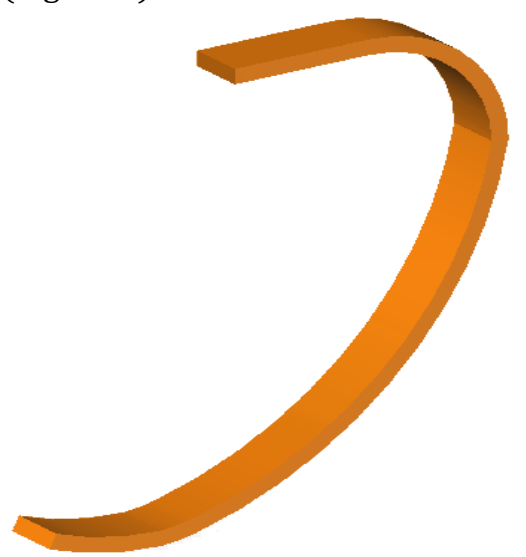

Figure 3: Geometry of a Flex-Run

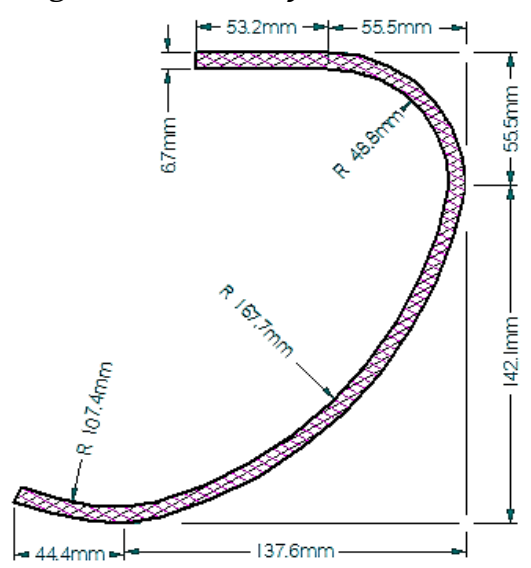

Figure 4: Front View of a Flex-Run 


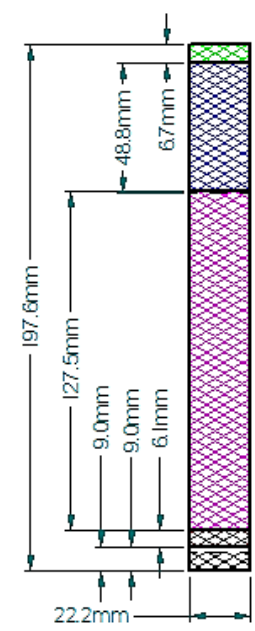

Figure 5: Side View of a Flex-Run

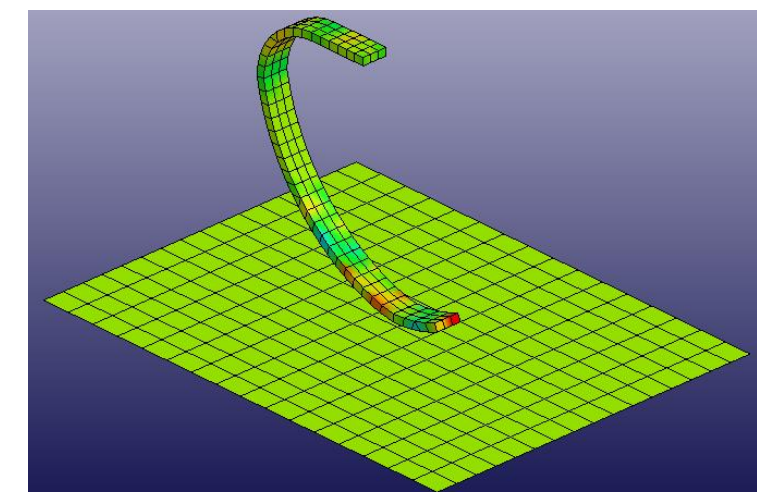

Figure: 6. LS-DYNA model of a Flexrun impacting on the ground surface

2.3 Evaluation of Acceleration, Velocities and Displacements

The acceleration evaluated at time $t$ is

$$
\left\{a_{i}\right\}=[M]^{-1}\left(\left[F_{t}^{i n t}\right]=\left[F_{t}^{n t}\right]\right)
$$

Where $\left[F_{t}^{\text {int }}\right]$ is the applied external and body force vector and $\left[F_{t}^{\text {int }}\right]$ is the internal force vector, which is given by

$$
F_{t}^{\text {int }}=\sum\left[\int_{\Omega} B^{T} \sigma_{n} d \Omega+F^{h g}\right]+F^{\text {mpact }}
$$

Where $F^{h g}$ is the hourglass resistance force and $F^{\text {impact }}$ is the contact force. The velocities and displacement are then evaluated as

$$
\begin{array}{r}
5\left\{V_{1+\Delta t / 2}\right\}=\left\{V_{1-\Delta t / 2}\right\}+\left\{a_{i}\right\} \Delta_{t} \\
\left\{u_{t+\Delta t / 2}\right\}=\left\{u_{t}\right\}+\left\{u_{t+\Delta t / 2}\right\} \Delta t_{t+\Delta t / 2}
\end{array}
$$

Where

$$
\begin{aligned}
\Delta t_{t+\Delta t / 2} & =\frac{1}{2}\left(\Delta t_{t}+\Delta t_{t+\Delta t}\right) \\
\Delta t_{t+\Delta t / 2} & =\frac{1}{2}\left(\Delta t_{t}-\Delta t_{t+\Delta t}\right)
\end{aligned}
$$

The geometry is by adding the displacement increments to the initial geometry $\left\{x_{0}\right\}$;

$$
\left\{x_{t+\Delta t}\right\}=\left\{x_{0}\right\}+u_{t+\Delta t}
$$

\section{RESULTS AND DISCUSSION}

The kinetic energy, strain, stress and displacement histories, as well as the resultant velocity response characteristics of the Flex Run,were shown at different impacting velocities. From the simulation results in Figure 7 , it was found that the effective strain shows a shifted step response, stabilising to different constant strain values at various impacting velocities. The minimum stability point is at $10 \mathrm{~m} / \mathrm{s}$ and $15 \mathrm{~m} / \mathrm{s}$ impacting velocities while the maximum point is at $20 \mathrm{~m} / \mathrm{s}$ impacting velocity. The middle value lies when the impacting velocity is $5 \mathrm{~m} / \mathrm{s}$. This displays a nonproportionality relation of the impacting velocity with effective strain.

The responses of the effective stress in Figure8 show an exponentially increasing triangular waveform observable within a time range. The same behaviour is observable for $5 \mathrm{~m} / \mathrm{s}, 10 \mathrm{~m} / \mathrm{s}$ and $15 \mathrm{~m} / \mathrm{s}$ impacting velocities while the $20 \mathrm{~m} / \mathrm{s}$ impacting velocity shows a higher stress level. The kinetic energy responses in Figure 9 for the different impacting velocities show a step function. The same behaviouris observed for all impacting velocities except for $10 \mathrm{~m} / \mathrm{s}$ where the kinetic energy has a lower constant value.

Comparing the displacement time histories with different impacting velocities in Figure 10, an exponentially increasing triangular waveform was found. Figure 11 show a damping exponential waveform. The maximum resultant velocities at various impacting velocities are at 0.05 s contact duration.

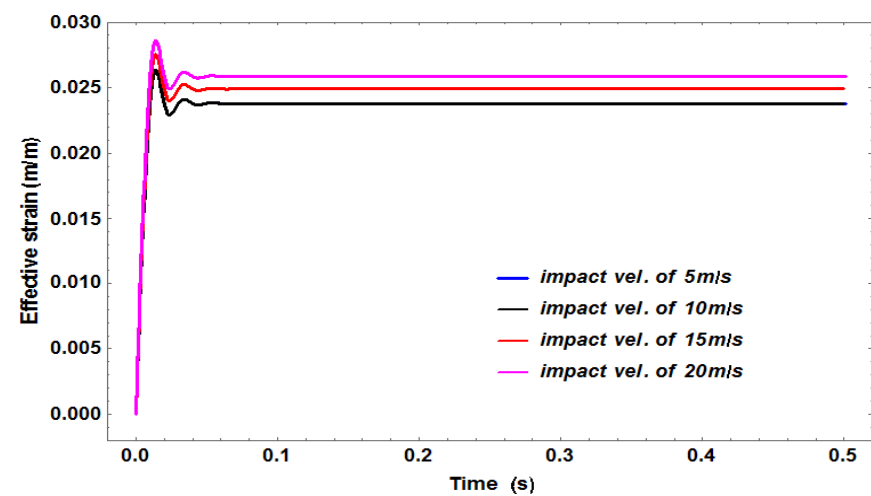

Figure 7. Effective strain response of the Flexrun at different impacting velocities

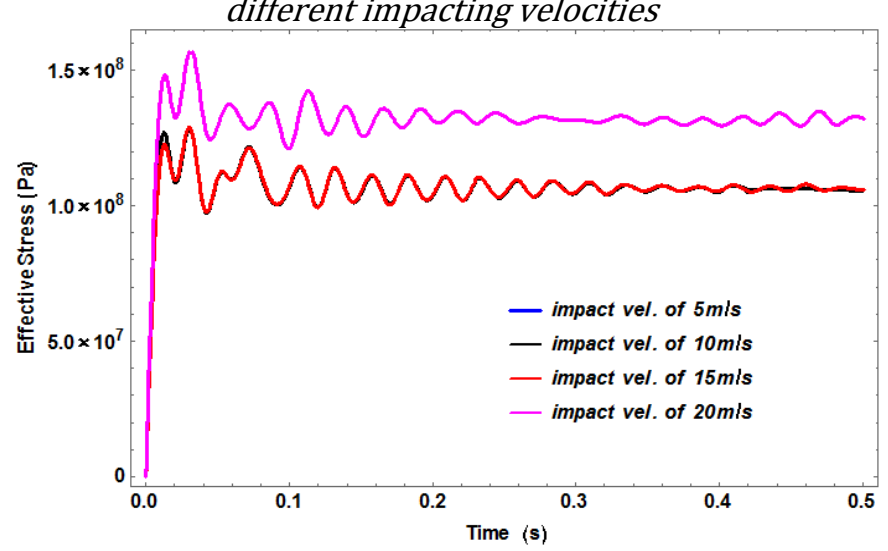

Figure 8: Effective stress responses of the Flexrun at various impacting velocities

Vol. 36, No. 2, April 2017 


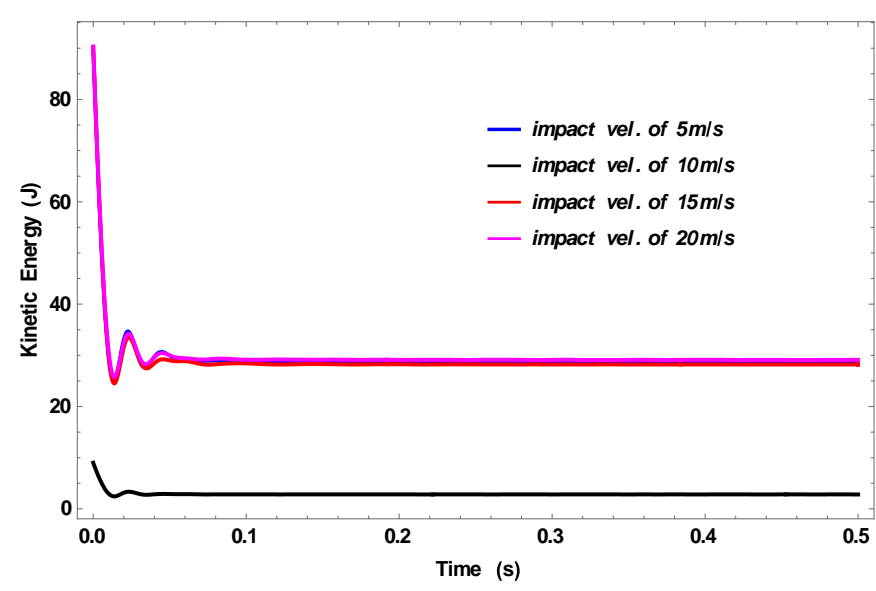

Figure 9:: Kinetic Energy responses of the Flexrun at

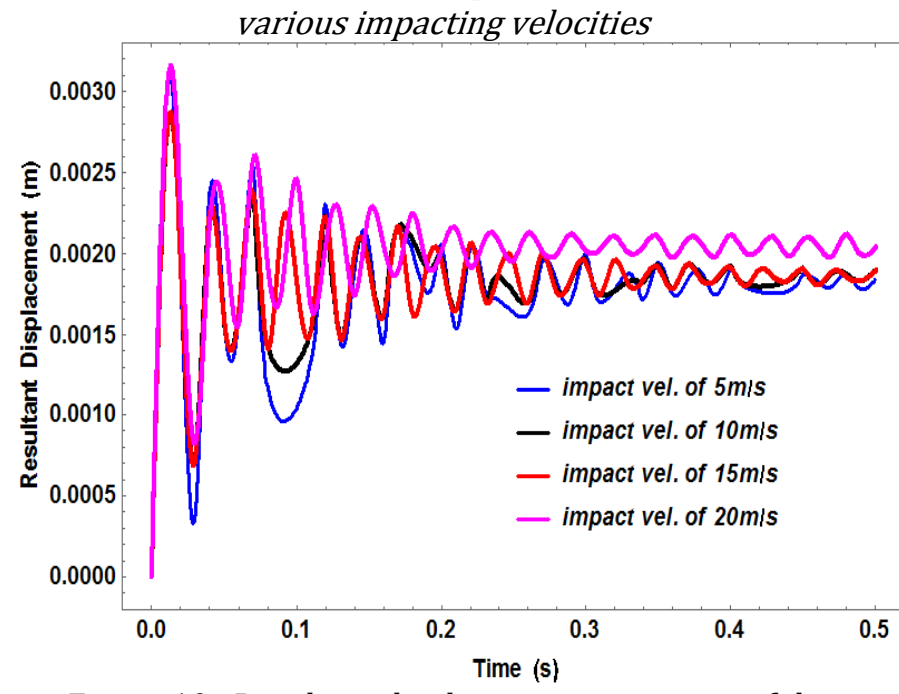

Figure 10: Resultant displacement responses of the Flexrun at various impacting velocities

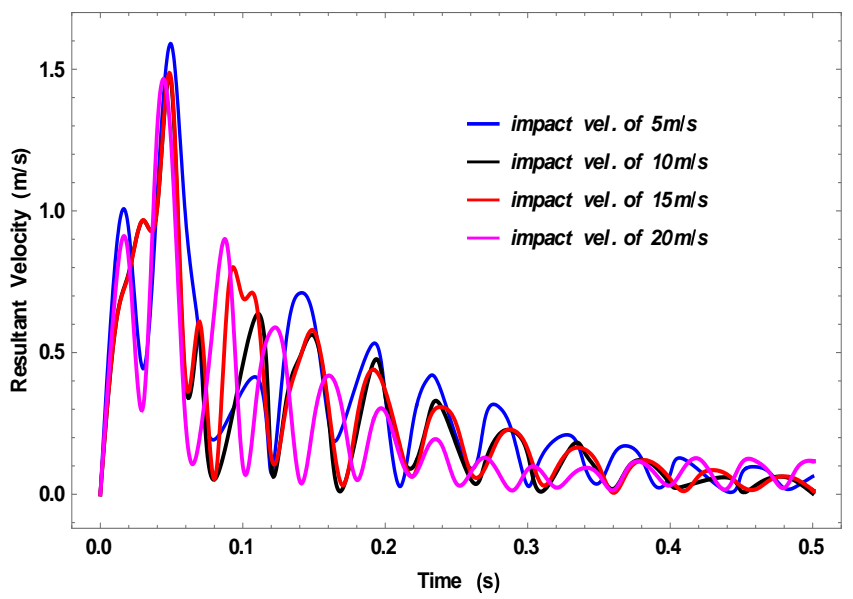

Figure 11: Resultant velocity responses of the Flexrun at various impacting velocities

\section{CONCLUSION}

In this research, impact analyses simulation of an impacting compliant system was conducted using LSDYNA. The finite element model was developed with necessary boundary conditions where the CAD model of the system had been done by Solid Edge ST6. The dynamic characteristics of the impacting compliant system were investigated. It was shown that the impacting velocity did not affect the stress and strain responses of the system up to a value of $15 \mathrm{~m} / \mathrm{s}$. The system will not fail as a result of increased impacting velocity below $15 \mathrm{~m} / \mathrm{s}$. This means that for super sprinters, the design consideration for impact failure should have an onset impact velocity value of $15 \mathrm{~m} / \mathrm{s}$. It is, therefore, important in the design of an impacting compliant system, to take cognizance of the adequate impact velocity values to avoid catastrophic failure. This can only be achieved through adequate impact analysis.

\section{REFERENCE}

[1] Howell,L. L.Compliant mechanisms: John Wiley \& Sons, 2001.

[2] https://www.msn.com/en-us/sports/moresports/the-day-in-sports-photos/ssBBuJmy7\#image $=1$. Accesssed November 2016.

[3] Phil Stevens, "Collision Course: Understanding the Role of Prosthetic Feet in Sparing the Sound SIde Limb", O\& P EDGE, Text, pp. 4-7, October 2014

[4] Morgenroth, D. C., Segal, A. D., Zelik, K. E., Czerniecki, J. M., GLute, G. K., Adamczyk, P. G., Orendurff, M. S., Hahn, M. E., Collins, S. H. and Kuo, A. D. "The effect of prosthetic foot push-off on mechanical loading associated with knee osteoarthritis in lower extremity amputees", Gait \& Posture, 34(4), pp. 502-7, 2011

[5] Hafner, Brian J., Joan E. Sanders, Joseph Czerniecki, and John Fergason. "Energy storage and return prostheses: does patient perception correlate with biomechanical analysis?." Clinical Biomechanics, 17(5), pp. 325-344, 2002.

[6] Griffiths, B. "Composite fan blade containment case," High Perform Compos, vol. 13, pp. 76-8, 2005.

[7] Hinton, M.J. and Soden, P.D. "Predicting failure in composite laminates: the background to the exercise", Composites Science and Technology, 58(7), pp.1001-1010, 1998.

[8] Richardson, M.O.W. and Wisheart, M.J., 1996. Review of low-velocity impact properties of composite materials. Composites Part A: Applied Science and Manufacturing, 27(12), pp.1123-1131.

[9] Cantwell, W.J. and Morton, J., 1991. The impact resistance of composite materials-a review. composites, 22(5), pp.347-362.

[10] G. Bibo and Hogg, P. "The role of reinforcement architecture on impact damage mechanisms and post-impact compression behaviour," Journal of Materials Science, vol. 31, pp. 1115-1137, 1996.

[11] Janapala, N., Chang, F., Goldberg, R. K., Roberts, G. D., and Jackson, K. E. "Crashworthiness of composite structures with various fiber 
architectures," in Proc 11th international LSDYNAŪ users conference, 2010.

[12]

http://www.si.com/olympics/2016/09/07/par alympics-rio-2016-inspiration-technology-doping Accesssed November 2016

[13] Miller, L. A. and Childress, D. S. "Analysis of a vertical compliance prosthetic foot," Journal of rehabilitation research and development, vol. 34, pp. 52, 1997.

[14] Saunders, M. M., Schwentker, E. P. Kay, D. B., Bennett, G., Jacobs, C. R., Verstraete, M. C. "Finite element analysis as a tool for parametric prosthetic foot design and evaluation. Technique development in the solid ankle cushioned heel (SACH) foot," Computer Methods in Biomechanics \& Biomedical Engineering, vol. 6, pp. 75-87, 2003.

[15] Gitter, A., Czerniecki, J. M., and DeGroot, D. M. "Biomechanical analysis of the influence of prosthetic feet on below-knee amputee walking," American Journal of Physical Medicine \& Rehabilitation, vol. 70, pp. 142-148, 1991.

[16] Curtze, C., Hof, A. L., van Keeken, H. G., Halbertsma, J. P., Postema, K., and Otten, B. "Comparative rollover analysis of prosthetic feet," Journal of biomechanics, vol. 42, pp. 1746-1753, 2009.
[17] South, B. J., Fey, N. P., Bosker, G., and Neptune, R. R. "Manufacture of energy storage and return prosthetic feet using selective laser sintering," Journal of biomechanical engineering, vol. 132, p. 015001, 2010.

[18] Frigo, C., Pavan, E., Bonacini, D., and Mangiante, B. "The Mechanical Characteristics of Lower Limb Prosthetic Feet Analysed Through Gait Analysis," in Primo Congresso Nazionale di Bioingegneria (Congresso GNB2008) Pisa, pp. 3-5, 2008.

[19]Bonnet, X., Pillet, H., Fodé, P., Lavaste, F., and Skalli, W. "Finite element modelling of an energy-storing prosthetic foot during the stance phase of transtibial amputee gait," Proceedings of the Institution of Mechanical Engineers, Part $H$ : Journal of Engineering in Medicine, vol. 226, pp. 70-75, 2012.

[20] Evans, G., Jones, B., McMillan, A., and Darby, M. "A new numerical method for the calculation of impact forces," Journal of Physics D: Applied Physics, vol. 24, p. 854, 1991.

[21] LS-DYNA. LSTC, "Theoretical Manual, Livermore Software Technology Corporation, Livermore," 2016.

22] Ogden, R. W.Non-linear elastic deformations: Courier Corporation, 1997. 